\title{
Platelet functions in relation to diet and serum lipids in British farmers ${ }^{\star}$
}

\author{
S RENAUD, R MORAZAIN†, F GODSEY, E DUMONT, I S SYMINGTON, \\ E M GILLANDERS, J R O'BRIEN
}

From INSERM, Unit 63, Lyon-Bron, France, Department of Nutrition, University of Montreal, Canada, Employment Medical Advisory Service, Dundee, and St Mary's Hospital, Portsmouth

SUMMARY Coagulation and platelet aggregation induced by thrombin, ADP, adrenaline, and collagen were studied in three contrasted groups, each of 20 to 22 middle-aged male farmers. Serum lipids were similar in the three groups. In the west of Scotland group, however, platelet reactivity was significantly greater than in the east of Scotland. This was associated with a dietary intake, evaluated by three different techniques, higher in saturated fat but also lower in polyunsaturated fat and alcohol. Platelet function in the southern England group also correlated with dietary fats and in addition inversely with calcium intake. On an individual basis in the 63 farmers, all the platelet function tests were significantly correlated with the intake of saturated fat regulated by that of calcium and alcohol.

The dietary effects on platelets appear to be mediated by the fatty acid composition of plasma

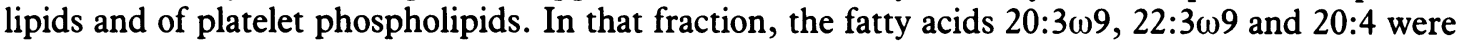
the most closely related to the platelet function tests. The trienoic acid 20:3 $\omega 9$, identified with essential fatty acid deficiency, was also correlated with the intake of saturated fat and calcium. In this study, platelet functions were more dependent upon the dietary factors associated with coronary heart disease such as saturated fats, calcium, and alcohol than upon serum lipids.

Animal studies have shown that prolonged feeding with saturated fats predisposes to thrombosis initiated in various ways. ${ }^{1}$ In man, platelet function can be modified by dietary changes ${ }^{2} 3$ and studies performed on French farmers have shown that platelet responses were more closely related than serum lipids to the intake of saturated fats and the known incidence of coronary heart disease in the region. ${ }^{45}$

Farmers were chosen for these studies because of their comparable life style. In addition, farmers take every meal at home and, consequently, precise evaluation of the food intake can be more easily achieved particularly since their diet does not appear to change much from day to day. The aim of the present pilot study performed in 1978 in the United Kingdom was to investigate in healthy subjects the relation between diet, serum lipids and platelet function in geographical areas with differing

\footnotetext{
* Supported by the Tobacco Council of Canada, the INSERM (contract CNAMTS) and the CETIOM organisations in France.

† Fellow of the McDonald Stewart Foundation, Montreal, Canada.

Received for publication 21 April 1981
}

incidences of coronary heart disease. ${ }^{6}$ Farmers were chosen from three areas: south west Scotland (coronary heart disease death rate per 100000 in men aged 35 to 44: 95); east Scotland (coronary heart disease death rate: 65 ), and south England (coronary heart disease death rate: 54$){ }^{6}$

Recommendations made by the Scottish Home and Health Department Working Party ${ }^{7}$ were that careful dietary studies were desirable within defined populations. This study attempts to parallel epidemiological work with detailed laboratory investigations.

\section{Subjects and Methods}

SUBJECTS

Healthy male farmers who were actively farming, and were born between 1 January 1933 and 31 December 1938 , in the region, were selected. All the farmers fulfilling the above criteria, identified through Health Centre records, within a radius of approximately 10 miles from the following small towns: Kirriemuir and Friockheim in east Scotland; Stranraer, in south west 
Scotland; Denmead, in south England, were asked to participate.

Sixty-nine farmers met the criteria and were contacted by their local Health Centre. Sixty-three agreed to participate and informed consent was obtained from all subjects, 52 of whom were also owners of their farm.

The project was approved by the British Medical Association Ethical Committee.

\section{DIETARY SURVEY}

The study was undertaken using a mobile laboratory with the same personnel and instrumentation as in previous studies. ${ }^{45}$ Each subject, was assessed in respect of his dietary habits and his state of health and nutrition in the following ways.

\section{(a) The 24-hour recall of diet}

This was performed one or several days before the weighing technique. Both the farmer and the lady of the house were present for the interview which also included questions about smoking habits.

\section{(b) Weighing technique and diet composite}

This was performed as in previous studies. The dietitian was present on one week day, at each of the subject's two main meals (midday and evening) and each of the food items and drinks was weighed before being eaten. An equal portion of this food was placed in a closed refrigerated container and similarly for the breakfast and any other food intake, and the subject's spouse was asked to keep an identical portion refrigerated. Each subject's daily food collection was mixed, ground (Waring Blender), and weighed, with two $180 \mathrm{~g}$ samples being taken and frozen for subsequent analysis by the Municipal Laboratory in Bordeaux (France), with the techniques already used. ${ }^{4}$ The food items were then coded by the dietitian before computer processing. The food table composition used was essentially the British table recently published, ${ }^{8}$ but with a number of meat products and fats such as margarine and dripping, being analysed for their fatty acid composition, in our laboratory.

\section{(c) Physical examination}

This was performed by a local physician, except for the anthropometric determinations (weight, height, 12 skinfolds) which were done by the dietitian. The blood pressure was determined by both the nurse of the team and the local physician.

COAGULATION AND AGgREgATION TESTS Before venesection $(130 \mathrm{ml})$ each subject fasted and refrained from smoking for 10 hours. The following tests were performed as in previous studies ${ }^{4}:$ (a) The recalcification plasma clotting time of platelet rich plasma without or with (Stypven time) the addition of Russell's viper venom $(1 / 100,000)$ (Sigma Chemical Co, Saint-Louis, Mo, USA); (b) the cephalin recalcification clotting time of platelet poor plasma; (c) the platelet factor 3 recalcification clotting time which is the clotting time of washed platelets resuspended in a standard platelet poor plasma; (d) the aggregation of platelet rich plasma with a platelet count of 300000 per $\mu$ l, in response to the following agents: thrombin, adenosine diphosphate, collagen, adrenaline bitartrate as in previous studies ${ }^{4} 5$ and in addition arachidonic acid. The arachidonate solution was prepared by diluting $50 \mathrm{mg}$ arachidonic acid (Sigma chemical Co) with $1.65 \mathrm{ml} \mathrm{NaOH}, 0.1 \mathrm{~N}$, sonicating for 10 seconds, and adding $14.85 \mathrm{ml}$ of complete tyrode. The solution was distributed in small containers, frozen and before use diluted to half with Tyrode to give a final concentration in platelet rich plasma of 70 and $35 \mu \mathrm{g} / \mathrm{ml}$.

The final determinations for both coagulation and aggregation were performed in a Rubel-Renaud recording aggrego-coagulometer (US patent no 4.116.564), a modification of Born's original turbidimetric technique. ${ }^{9}$

\section{LIPID ANALYSIS}

Fatty acid analysis of the diet, plasma total lipids, and platelet total phospholipids were performed after lipid extraction and methylation as previously reported, ${ }^{4}$ by gas liquid chromatography except that the 6 foot glass columns were packed with $10 \%$ Supelco 2340 on $100 / 120$ chromosorb W-AW and with temperature programming $\left(150^{\circ}-210^{\circ} \mathrm{C}, 2^{\circ} / \mathrm{min}\right)$. The platelet total phospholipids were separated by thin layer chromatography in one dimension on silica gel 60F-254 aluminium foils (Merck, E., Darmstadt, Germany) with the following solvent mixture: petroleum ether-diethyl ether-acetic acid (90:30:2, $\mathrm{v} / \mathrm{v})$. Total serum cholestrol and triglycerides were determined as in previous studies ${ }^{4}$ and the high density lipoprotein-cholesterol by the Technicon automated technique after heparin-manganese precipitation. ${ }^{10}$

The statistical significance of the results was evaluated by Student's $t$ test, and the regression analysis, uni- or multivariate, performed by computer, according to the method of Efroymson. ${ }^{11}$

\section{Results}

In Fig. 1 are reported different variables studied in the farmers from the three regions. None of them except the cigarette consumption is significantly different from one region to another, in particular 


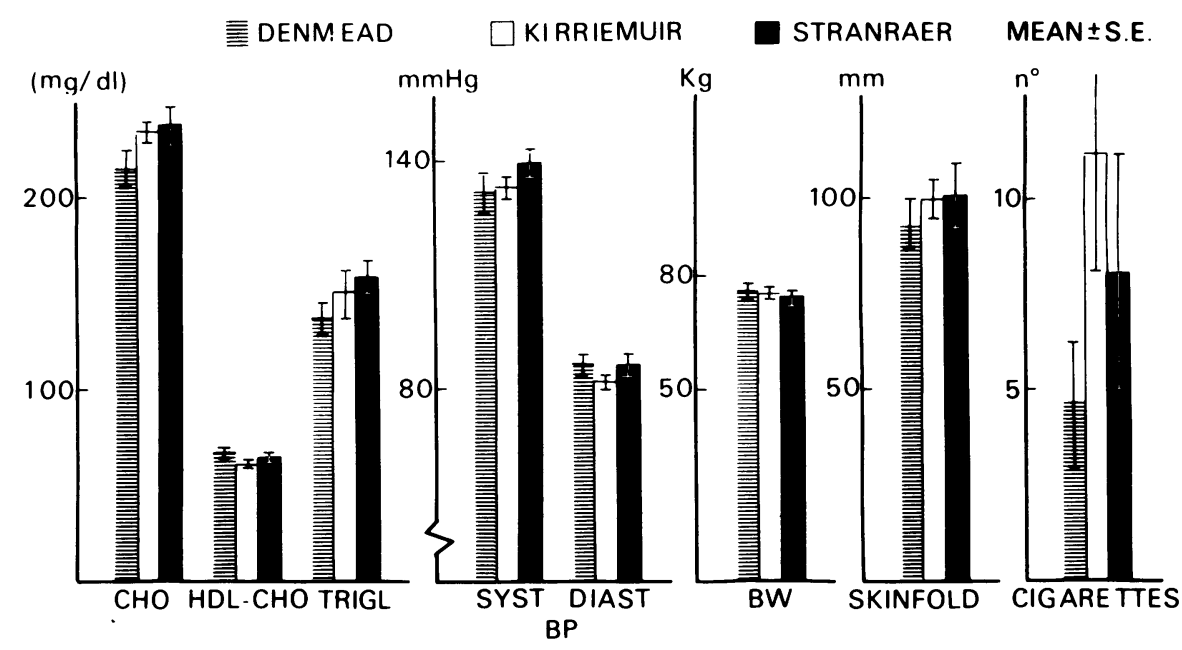

Fig. 1 Comparison of certain parameters between the three groups of British farmers. $C H O$, serum total cholesterol; $H D L-C H O$, serum HDL-cholesterol; TRIGL, serum triglycerides; SYST, systolic blood pressure; DIAST, diastolic blood pressure; BW, body weight.

serum cholesterol, HDL-cholesterol, and triglycerides.

From the haematological results (Fig. 2) it can be seen that the plasma clotting times and the platelet factor 3 recalcification clotting time (evaluating the platelet clotting activity) are similar at Denmead and at Kirriemuir. By contrast at Stranraer, both tests are significantly shorter (accelerated) $(p<0.001)$ than in the two other regions. The cephalin recalcification clotting time, which evaluates the activity of the plasma clotting factors, does not show any significant difference between the three regions. The Stypventime of platelet rich plasma was $26 \cdot 6 \pm 1 \cdot 1$ s at Denmead, $28.4 \pm 0.8 \mathrm{~s}$ at Kirriemuir, and $23.9 \pm 0.7 \mathrm{~s}$ at Stranraer (mean $\pm \mathrm{SE}$ ). The values obtained at Stranraer are significantly accelerated when compared with those of Kirriemuir $(p<0.001)$ and of Denmead $(p<0.005)$. All the tests of aggregation are significantly lower at Kirriemuir than those at Stranraer and Denmead. Except for thrombin induced aggregation which is lower at Denmead, the results of the other aggregation tests are similar at Denmead and at Stranraer.

The correlations on an individual basis between the various haematological tests are given in Table 1 . The italics demonstrate two series of highly significant correlations.

(a) Those between the clotting tests and thrombin aggregation: these two different tests were performed by two different technicians.

(b) The correlations between the other tests of aggregation: none of these tests, however, are significantly correlated with serum cholesterol, HDLcholesterol, or triglycerides.

The fatty acid composition of plasma total lipids is shown in Fig. 3. The following ratio saturated + monounsaturated/linoleic + linolenic acids appears to be related to platelet factor 3 recalcification clotting time and to thrombin-induced aggregation. The correlation coefficient between that ratio and thrombin induced aggregation is $\mathrm{r}=0.26(\mathrm{p}<0.05)$. It rises to $r=0.32(p<0.01)$ when the interference of plasma triglyceride concentration is removed.

By contrast, the other tests of aggregation seem to be related to the fatty acid ratio arachidonic/lionoleic on a group basis though no significant correlation could be obtained on an individual basis.

Table 1 Correlations ( $r$ ) between certain blood variables in 63 farmers

\begin{tabular}{lcrrrrr}
\hline & $P C T$ & $T H R$ & $A D P(P)$ & $E P I(P)$ & $C O L L$ & $F_{3}-C T$ \\
\hline F3-CT & 0.99 & 0.62 & 0.27 & 0.22 & 0.26 & \\
STYPVEN & 0.65 & 0.50 & 0.21 & 0.40 & 0.20 & 0.66 \\
ADP(S) & & 0.39 & 0.70 & 0.53 & 0.84 & 0.28 \\
EPI(S) & & 0.17 & 0.45 & 0.74 & 0.71 & 0.15 \\
AA & & 0.23 & 0.31 & 0.35 & 0.46 & 0.23 \\
CHO & & -0.12 & -0.18 & -0.12 & -0.19 & 0.11 \\
HDL-CHO & & 0.11 & 0.13 & 0.05 & 0.03 & 0.00 \\
Trigel & & -0.07 & -0.22 & -0.03 & 0.03 & 0.22 \\
\hline
\end{tabular}

Abbreviations as in Fig. 1 and 2.

STYPVEN = Stypven-time of platelet rich plasma

Highly significant $(p<0.001)$ correlations are in italics $(r=0.25, p<0.05 ; r=0.32$, $\mathrm{p}<0.01 ; \mathrm{r}=0.41, \mathrm{p}<0.001)$. 


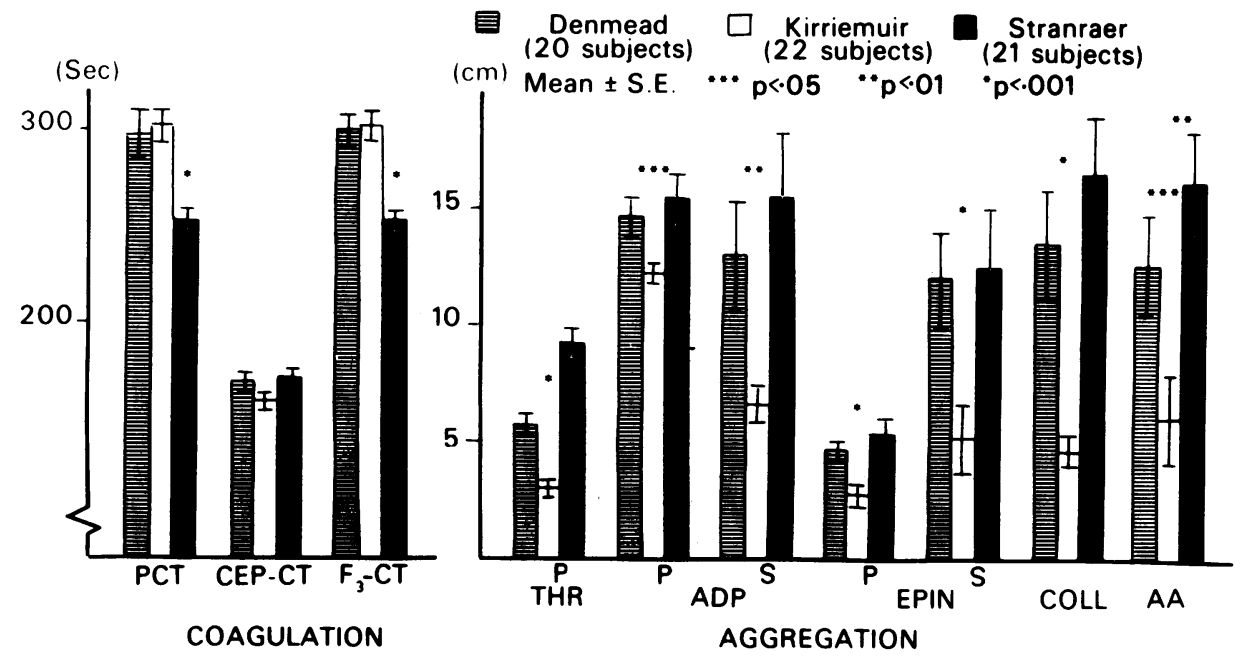

Fig. 2 Haematological results. PCT, recalcification plasma clotting time of platelet rich plasma (evaluates the whole blood clotting activity); CEP-CT, cephalin clotting time of platelet poor plasma (evaluates the global activity of the plasmatic clotting factors); $F_{3}-C T$, recalcification clotting time of platelets washed and resuspended in a standard platelet poor plasma (evaluates solely the platelet clotting activity, that is $\mathrm{PF}_{3}$ ). Aggregation (performed in citrated platelet rich plasma, 300000 platelets/ $\mu \mathrm{l}$ ). THR, thrombin (final concentration in platelet rich plasma, $0 \cdot 12 \mathrm{NIH}$ Units per ml);ADP, adenosine diphosphate $\left(0.92 \times 10^{-6}\right.$ mol in platelet rich plasma); $P$, primary aggregation; $S$, secondary aggregation; EPIN, adrenaline $\left(0.6 \times 10^{-6}\right.$ mol in platelet rich plasma); $C O L L$, collagen $(126 \mu \mathrm{g} / \mathrm{ml}$ platelet rich plasma); AA, arachidonic acid (70 $\mathrm{gg} / \mathrm{ml}$ platelet rich plasma). Extent of aggregation for all tests as the maximal deflection in $\mathrm{cm}$.

Results of the dietary habit evaluation are reported in Fig. 4 (diet composite chemical analysis of a 24-hour period) and in Fig. 5 (past recall and weighing technique based on two different days). Fig. 6 shows that the three methods yield closely similar results.

The intake of polyunsaturated fat, with both techniques, was significantly lower at Stranraer than at Kirriemuir and also than at Denmead as evaluated by the chemical analysis. At Kirriemuir, the intake of saturated fat was significantly lower whether alcohol was included or not included in the calculation of calories (Table 2). In practical terms, the mean intake of visible fat in the form of butter, cream, and vegetable fat (margarine + oil) was in $g$ /day (mean \pm SE) of $40 \pm 3 \cdot 5,24 \pm 9 \cdot 0$ and $10 \pm 2 \cdot 7$, respectively, at

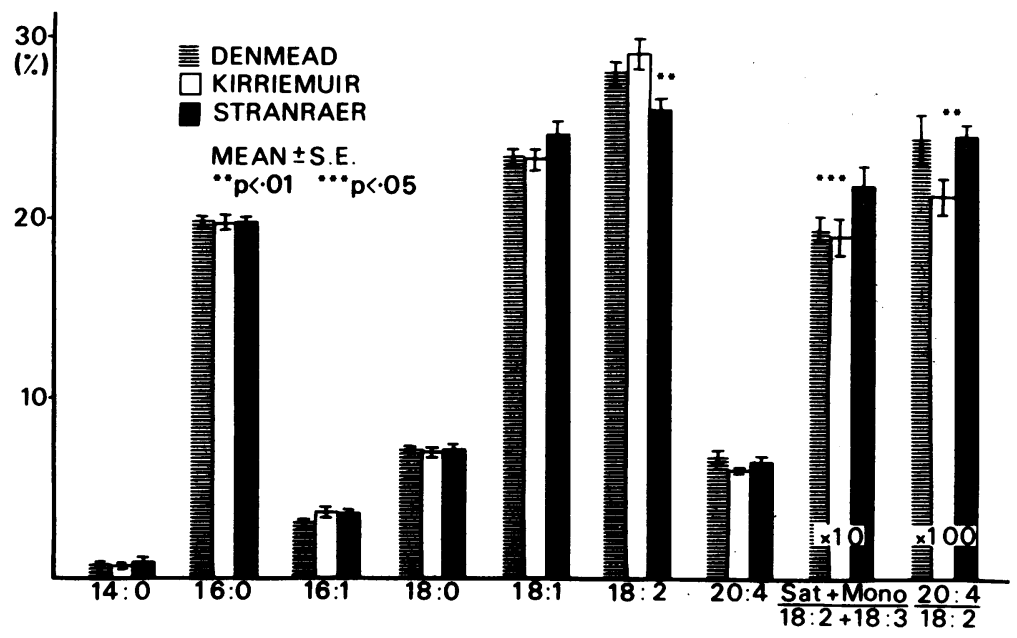

Fig. 3 Fatty acid composition of the plasma total lipids. Saturated $($ Sat $)=$ myristic $(14: 0)+$ palmitic $(16: 0)+$ stearic $(18: 0)$; Monounsaturated $($ Mono $)=$ palmitoleic $(16: 1)+$ oleic $(18: 1)$ + eicosenoic $(20: 1)$ 


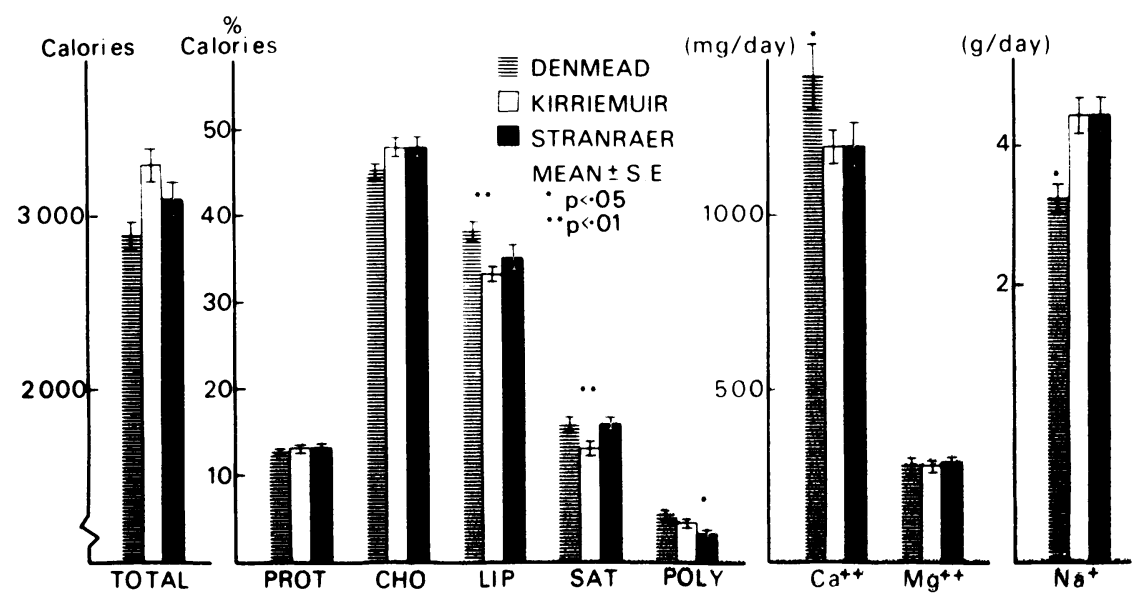

Fig. 4 Mean nutrient intake by chemical analysis of a 24 hour diet composite in the three groups. PROT, proteins; CHO, carbohydrates; SAT, saturated fatty acids; LIP, total lipids; POLY, polyunsaturated fatty acids.

Stranraer, whereas it was of $14 \cdot 5 \pm 5 \cdot 0,3 \cdot 1 \pm 2 \cdot 7$ and $44 \pm 6 \cdot 1$ at Kirriemuir.

Several univariate correlations between diet components and the blood variables examined in the 63 farmers were highly significant as shown in Table 3. Of particular interest are the correlations between: (a) dietary cholesterol, the alcohol intake, and platelet functions as well as high density lipoprotein cholesterol; (b) dietary cholesterol and platelet factor 3 recalcification time and serum cholesterol; (c) the saturated fat intake evaluated by two different techniques and the platelet function tests.

In multivariate analysis, considering the effect of linoleic acid added to that of the saturated fatty acids, only slightly improved (particularly with the chemied analysis evaluations) the correlations with platelet function tests. By contrast, the correlation with total serum cholesterol became significant (chemical analysis) with a negative sign for linolete acid. The inclusion of calcium together with saturated fats made no substantial change to the correlations with the serum lipids (cholesterol, triglycerides; high density lipoprotein cholesterol) whereas it significantitly $(p<0.05)$ improved correlations with the platelet factor 3 fecalcification time and thrombinaggregation; with the nutrient intake determined by chemical andilysis.

Concerning platelet phospholipid fatty acid composition (Fig. 7), only a few minor differences could be observed between the regions, in the $20: 3019 ; 20: 4$,

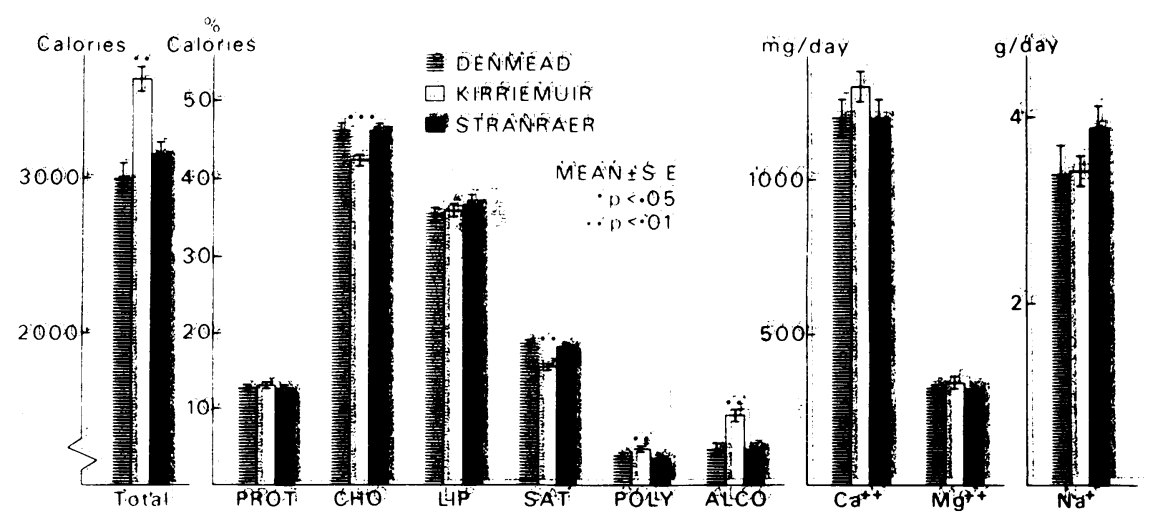

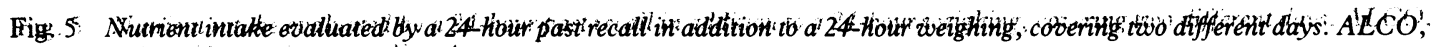

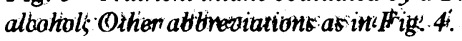




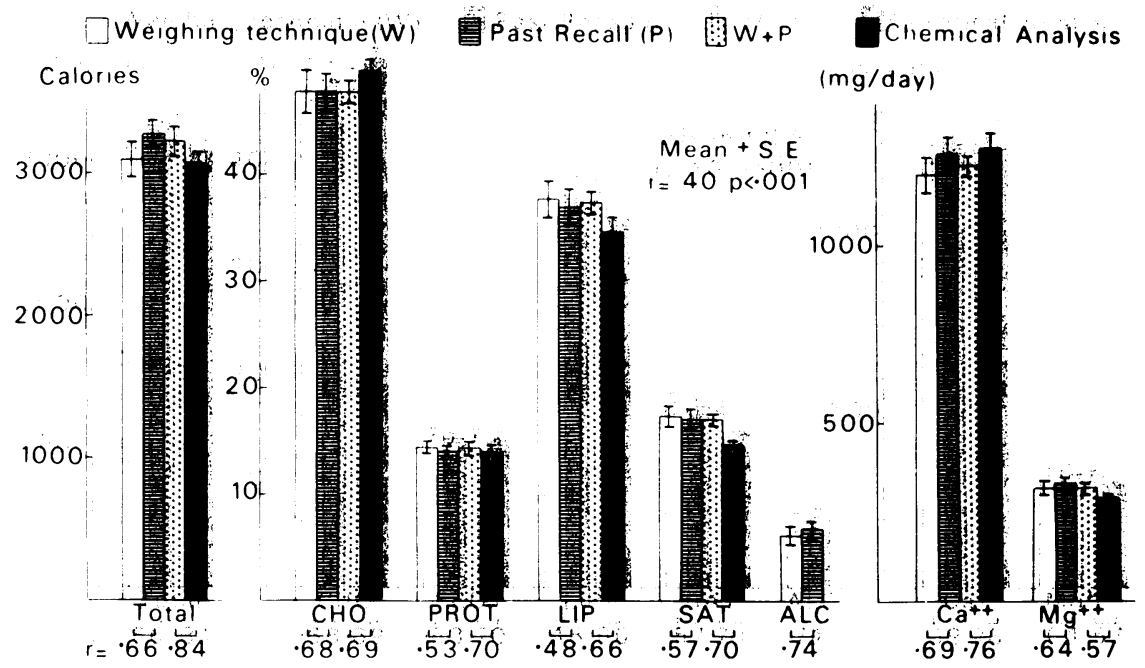

Fig. 6 Nutrient intake evaluation in the 63 British farmers stidied in 1978. Comparison was between the weighing technique and the past recalt, performed on two different days, and betrieen the chemical analysis and the medn result of the weighing + recatl.

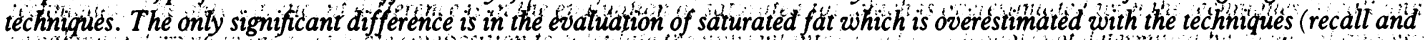
weighing) referring to the food table composition to cátcutate the nutrient intake. ALC, altcohot (not determined by chemical analysis). Other abbreviations as in Fig. 4.

$22: 5 \omega 3$, the ratio $20: 3 \omega 9+22: 3 \omega 9 / 18: 2$, and in the $18: 0$ dimethyl acetal. Of special interest appears to be the fatty acids $20: 3 \omega 9,22: 3 \omega 9$ (which runs parallel to $20: 3 \omega 9)$ and $20: 4$, since they dre significantly correlated with the platelet function tests on an individual basis (Table 4), Moredver, 20:369 in platelet phospholipids was also significantly correlated with the intake of saturated fat $(\mathrm{r}=0.27$ ) (Table 5). When in addition to saturated fat, the calcium intake was considered in trivariate anklysis, the coefficient correlation increased from 0.27 to 0.33 , with a negative sign for calcium.

Table 2 Saturated fat intake (\% calories) in three regions inctuding or not including alcohol

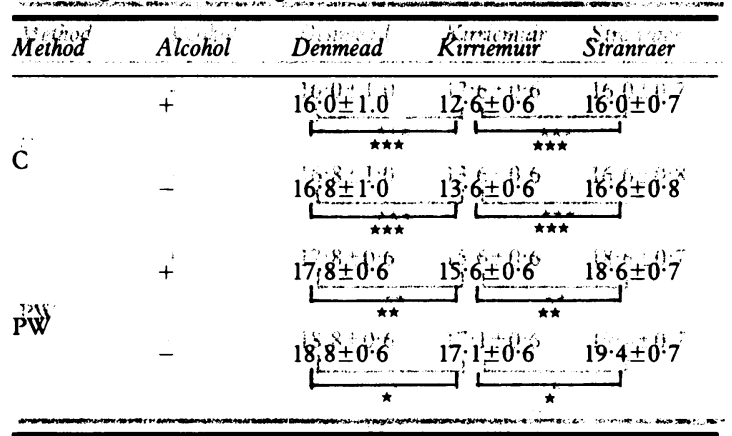

Cichememical analysis;

PW, z4thour past recall +24 hour weighing.

Results $=M$ Mean $\pm S E ; \mathrm{s}^{\prime}<0.05 ; \star \star \mathrm{p}<0.02 ; \star \star \star \mathrm{p}<0.0 \mathrm{~d}^{1}$

\section{Discussion}

These results on serum lipids and platelet function in Scottish farmers follow the same pattern as in the French groups in areas of high and low risk for coronary heart disease. ${ }^{4}$ While there was no difference in the lipaemia (including HDL-cholesterol) between the two regions despite a much higher intake of saturated and a lower intake of polyunsaturated fatty acids in west Scotland, the platelet functions were thuch lower in east Scotland, in the subjects examined. A second study (to be reported elsewhere) performed in 1979, again in Scottish farmers, but only on smokers this time, confirmed completely the present study on the lower platelet function and lower fat intake in eatst Scottand, even though the areas investigated were different (Inverurifie atld Girvan'):

The differenter noted with the diet surveys is further substantiated by the fatty acid composituon' of the plasma total lipias; which shows' a significtunty lower level of linoleit atid in west Scotland the region with the higher coronary heart disease risk and a slithtly higher level of oleic acid, which is the usulal pattern observed in atherosclerotit pattients with or without ${ }^{3}$ dembnstrated platelet hyperactivity.

Similar results were also reported recentily in a comparison between men from Eabiburgh ath from Stockibolm. ${ }^{14}$ Thoúgh serum cholesterrol was iadenticial it the two cities, a striking difference in the level of linoleic acid in plasma lipids and alupose tissue was 
Table 3 Correlations $(r)$ between blood parameters and diet components in 63 British Farmers studied in three regions

\begin{tabular}{|c|c|c|c|c|c|c|c|c|c|}
\hline Diet & Method & $F_{3}-C T$ & $T H R$ & $A D P$ & $E P I$ & $C O L L$ & Cho & $H D L$ & $T R I G L$ \\
\hline Alco & PW & 0.07 & $-0 \cdot 16$ & -0.31 & -0.29 & -0.26 & 0.05 & 0.25 & 0.01 \\
\hline Cho & PW & 0.34 & 0.22 & 0.02 & 0.14 & 0.08 & 0.30 & 0.06 & 0.14 \\
\hline \multirow{2}{*}{ SAT } & PW & 0.31 & 0.19 & 0.07 & 0.23 & 0.32 & 0.13 & -0.05 & $0 \cdot 18$ \\
\hline & C & 0.35 & $0 \cdot 21$ & $0 \cdot 26$ & $0 \cdot 25$ & 0.43 & 0.05 & 0.05 & -0.08 \\
\hline \multirow{2}{*}{$\star$ Sat and 18:2 } & PW & $0.40(-)$ & $0 \cdot 24(-)$ & $0 \cdot 27(+)$ & $0 \cdot 24(-)$ & $0.32(+)$ & $0.22(-)$ & $0.06(-)$ & $0 \cdot 20(+)$ \\
\hline & C & $0.36(-)$ & $0 \cdot 22(-)$ & $0 \cdot 28(+)$ & $0 \cdot 26(+)$ & $0.43(+)$ & $0 \cdot 28(-)$ & $0.08(-)$ & $-0 \cdot 14(-)$ \\
\hline \multirow{2}{*}{ Sat and $\mathrm{Ca}^{++}$} & PW & $0 \cdot 34(-)$ & $0 \cdot 25(-)$ & $0 \cdot 22(+)$ & $0.33(+)$ & $0.45(+)$ & $0 \cdot 15(+)$ & $0.06(-)$ & $0 \cdot 22(-)$ \\
\hline & $\mathrm{C}$ & $0.42(-)$ & $0 \cdot 32(-)$ & $0 \cdot 28(+)$ & $0.31(+)$ & $0.51(+)$ & $0 \cdot 17(-)$ & $0.05(-)$ & $-0.12(-)$ \\
\hline
\end{tabular}

^ Trivariate analysis. Abbreviations as in Fig. 1-5. Cho, cholesterol; ALCO, alcohol; PW, past recall + weighing technique; C, chemical analysis.

Significant correlations are italicised $(r=0.25, p<0.05 ; r=0.32, p<0.01 ; r=0.41, p<0.001)$. In parentheses, the sign of $18: 2$ or $\mathrm{Ca}^{++}$in the multivariate analysis.

observed. This decrease in linoleic acid appears to be associated with the three times greater mortality rate from coronary heart disease in Edinburgh. ${ }^{14}$ The correlation between the plasma fatty acid composition and the platelet function tests is of interest; it confirms our previous observations, ${ }^{12}$ and emphasises the obvious dependence of platelet functions on the diet and plasma fatty acid composition.

The difference in the dietary habits between the groups in east and west Scotland appears to be mostly the result of the following.

(1) The visible fats which are essentially dairy products in the west, and vegetable fats (oil and polyunsaturated margarines) in the east, at least in the subjects studied. Dairy farming is the main activity in south Scotland and ease of access to dairy products may be of importance in the type of diet consumed. It seems that a change from dairy to beef farming has taken place in east Scotland in the past decade.

The prominent influence of saturated fats (and eventually of dietary cholesterol) on platelet functions is substantiated by the correlations observed in the present study between these nutrients and the platelet function tests. Similar correlations have been found in French farmers. ${ }^{4515}$

(2) The higher intake of alcohol in the east Scotland group. Alcohol, in the present study, was inversely correlated with some of the platelet function tests and

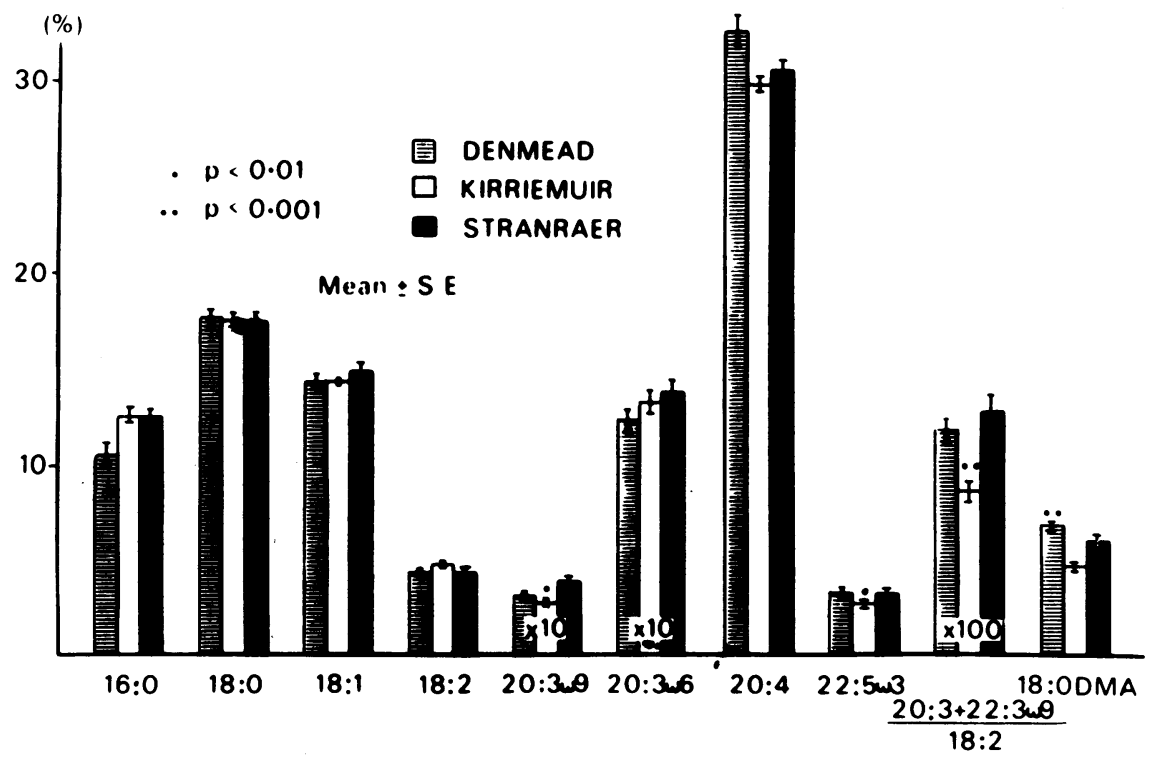

Fig. 7 Fatty acid composition of the platelet total phospholipids. DMA, Dimethyl acetal. 
Table 4 Prospholipid fatty acids most closely related to platelet function tests in 63 British farmers, univariate analysis ( $r$ ).

\begin{tabular}{lllr}
\hline & $20.3 \omega 9$ & $22.3 \omega 9$ & \multicolumn{1}{l}{20.4} \\
\hline F.CT & 0.46 & 0.18 & -0.10 \\
THR & 0.35 & 0.43 & 0.16 \\
ADP & 0.13 & 0.13 & 0.27 \\
COLL & 0.19 & 0.37 & 0.26 \\
EPI & 0.30 & 0.35 & 0.27 \\
\hline
\end{tabular}

Abbreviations and significance as in Fig. 2 and Table 3.

positively correlated with the level of high density lipoprotein cholesterol, a result similar to that obtained in French farmers. ${ }^{5}$ Alcohol is known to increase the level of high density lipoprotein cholesterol $^{16}$ and inhibits platelet functions both in $\operatorname{man}^{17}$ and in animals. ${ }^{5}{ }^{15}$ Consequently, the higher intake of alcohol in the east Scotland group might be partly responsible for the lower response of platelets to aggregation by ADP, adrenaline, and collagen observed in this region. In southern England (Denmead), a region in which the incidence of coronary heart disease does not appear to be much different from that of east Scotland, at least in the general population, ${ }^{6}$ only the clotting activity of platelets and, to some extent, the response to thrombin, were comparable, among the tests performed, to the results obtained in East Scotland. It has to be emphasised that it is only these two tests that we have repeatedly found to be closely related to thrombosis in animals and to coronary heart disease in man. ${ }^{14} 18$

The lower response in Denmead, of the platelet clotting activity and of the thrombin aggregation could be the result of the intake of calcium or of linoleic acid, both being significantly higher when determined by chemical analysis in this region as compared with west Scotland. Chemical analysis is the only technique which can precisely evaluate the

Table 5 Correlations ( $r$ ) between certain platelet phospholipid fatty acids, diet components and platelet function tests in 63 British farmers studied in 1978.

\begin{tabular}{lrr}
\hline Platelet & \multicolumn{1}{c}{} \\
P lipids & $20: 3 \omega 9$ & $18: 2$ \\
\hline Diet & & \\
18:2 & -0.21 & 0.35 \\
SAT & 0.27 & -0.14 \\
SAT-Ca & 0.33 & -0.15 \\
Blood test $_{\text {F }}$-CT & & \\
THR & 0.46 & 0.11 \\
ADP & 0.35 & -0.09 \\
\hline
\end{tabular}

$\star$ Trivariate analysis

Abbreviations and significance as in Fig. 2 and Table 3. intake of: (a) minerals such as calcium which depend on the local source of water; (b) polyunsaturated fats since in margarines and prepared food, the amount of polyunsaturated can change conspicuously in a short time; (c) lipids which vary according to the way the meat is cooked. ${ }^{19}$

Multivariate analysis of the results from the diet composite chemical analysis suggests that the saturated fat induced hyperactivity of some platelet functions (platelet factor 3 recalcification time, thrombin) was inhibited mainly by dietary calcium. This has been confirmed in more extensive studies, in French farmers ${ }^{5} 15$ as well as in animal studies. ${ }^{15}$ Thus, the protective effect of dietary calcium on platelet functions, probably by promoting the excretion of long chain saturated fats as reported in animals and man, ${ }^{20}$ a result that we have confirmed recently in animal studies (to be published elsewhere) might be consistent with the known protective effect associated with hard water on coronary heart disease. $^{21}$

Concerning the mechanisms involved in the platelet hyperactivity induced by dietary fats, we have previously shown that it seems to depend, in animals ${ }^{22}$ and man, ${ }^{414}$ mainly on the increase in the platelet phospholipids of oleic acid and its trienoic derivative 20:3 $\omega 9$. In the present study, 20:3 $\omega 9$, $22: 3 \omega 9$, and 20:4 were correlated on an individual basis with the platelet function tests. In addition, the percentage of 20:3 $\omega 9$ in the platelets was also directly dependent upon the intake of saturated fat, and inversely related to that of calcium, as for the platelet function tests.

While the role of 20:4 in the platelet phospholipids seems to be obvious as the precursor of endoperoxide for aggregations dependent upon prostaglandins (adrenaline, collagen), we have no definite explana-

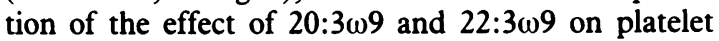
functions. Nevertheless the potential detrimental

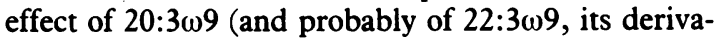
tive) which is specifically increased in essential fatty acid deficiency, ${ }^{23}$ has been consistently observed in human, ${ }^{413}$ and animal studies ${ }^{22} 24$ in relation to thrombosis, atherosclerosis, and coronary heart disease. Deficiency in essential fatty acids has been recently emphasised ${ }^{25}$ in relation to atheroma in man, but attention has been focused, until now, on the deficiency in 18:2 or its derivatives ${ }^{13}$ rather than on the possible noxious effects of 20:3 $\omega 9$.

Finally, in the present investigation, in which the smokers studied had not smoked for 10 hours before blood removal, no relation could be found between cigarette smoking and any of the platelet functions examined. In the additional studies conducted in 1979 on smokers from two Scottish areas, however, we have observed in confirmation of Levine ${ }^{26}$ that most 
of the platelet function tests were much increased when performed 10 minutes after smoking one cigarette. ${ }^{27}$ This effect was additive to the hyperactivity resulting from the saturated fat diet.

\section{References}

1 Renaud S. Dietary fats and arterial thrombosis. Thromb Res 1974 ; 4, suppl 1: 25-35.

2 Iacono JM, Binder RA, Marshall MW, Schoerne NW, Jencks JA, Mackin JA. Decreased susceptibility to thrombin and collagen platelet aggregation in man fed a low fat diet. Haemostasis 1974; 3: 306-18.

3 O'Brien JR, Etherington MD, Jamieson S. Acute platelet changes after large meals of saturated and unsaturated fats. Lancet 1976; i: 878-80.

4 Renaud S, Dumont E, Godsey F, Suplisson A, Thevenon C. Platelet functions in relation to dietary fats in farmers from two regions of France. Thromb Haemostas 1978; 40: 518-31.

5 Renaud S, Morazain R, McGregor L, Baudier F. Dietary fats and platelet functions in relation to atherosclerosis and coronary heart disease. Haemostasis 1979; 8: 234-51.

6 Fulton M, Adams W, Lutz W, Oliver MF. Regional variations in mortality from ischaemic heart and cerebrovascular disease in Britain. Br Heart $91978 ; 49 ;$ 563-8.

7 Anonymous Scottish Hearts (Editorial). Lancet 1979; ii: 726-7.

8 Paul AA, Southgate DAT, McCance and Widdowson's. The compasition of foods. Amsterdam, New York, and Oxford; Elsevier, 1978.

9 Born GVR, Cross MJ. The aggregation of blood platelets. F Physiol (Lond) 1.963; 168: 178-95.

10 Warnick GR, Albers JJ. A comprehensive evaluation of the heparin-manganese precipitation procedure for estimating high density lipoprotein cholesterol. $\mathcal{f}$ Lipid Res 1978; 19:65-76.

11 Efroymson MA. Multiple regression analysis. In: Ralston A, Wilf HS, eds. Mathematical methods for digital computers, vol. 1. New York: Wiley, 1960: 191-203.

12 Renaud S, Kuba K, Goulet C, Lemire $\mathrm{Y}$, Allard C. Relationship between fatty-acid composition of platelets and platelet aggregation in rat and man. Relation to thrombosis. Circ Res 1970; 26; 553-64,

13 Kingsbury KJ, Brett C, Stovold R, Chapman A, Anderson J, Morgan DM. Abnormal fatty acid composition and human atherosclerosis. Postgrad Med 1974; 50; 425-40.
14 Logan RL, Riemersma RA, Thomson M, et al. Risk factors for ischaemic heart-disease in normal men aged 40. Edinburgh-Stockholm study. Lancet 1978; i: 945-55.

15 Renaud S, Dumont E, Godsey F, McGregor L, Morazain R. Effects of diet on blood clotting and platelet aggregation. In Nutrition in the 1980's, New York, Alan R Liss, 1981.

16 Castelli WP, Doyle JT, Gordon T, et al. Alcohol and blood lipids. Lancet 1977; ii: 153-5.

17 Haut MJ, Cowan DH. The effect of ethanol on hemostatic properties of human blood platelets. Am $\mathcal{F}$ Med 1974; 56: 22-33.

18 Repaud S, Gautheron P, Arbogast R, Dumont E. Platelet factor 3 activity and platelet aggregation in patients submitted to coronarography. Scand $\mathcal{H}$ Haematol $1973 ; 12: 85-92$.

19 Whiting MG, Leverton RM. Reliability of dietary appraisal: comparisons between laboratory analysis and calculation from tables of food values. Am $\mathcal{F}$ Public Health 1960; 50: 815-23.

20 Yacowitz H, Fleischman AI, Bierenbaum ML. Effects of oral calcium upon serum lipids in man. Br Med.F 1965; i: $1352-4$.

21 Morris JN, Crawford MD, Heady JA. Hardness of local water-supplies and mortality from cardiovascular disease. Lancet 1961 ; i: 860-2.

22 Gautheron P, Renaud S. Hyperlipemia induced hypercoagulable state in rat. Role of an increased activity of platelet phosphatidyl serine in response to certain dietary fatty acids. Thromb Res 1972; i: 353-70.

23 Holman RT. The fatio of trienoic: tetraenoic acids in tissue lipids as a measure of essential fatty acid requirement. $f$ Nutr 1960: 70: 405-11.

24 MeGregor L, Morazain R, Renaud S, A comparison of the effects of dietary short and long chain saturated fatty acids on platelet functions, platelet phospholipids, and blood coagulation in rat. Lab Invest 1980; 43: 438-42.

25 Oliver MF. Fats and atheroma (letter). Br Med f 1979; i: 8.89.90,

26 Levine PH, An acute effect of cigarette smoking on platelet function. A possible link between smoking and arterial thrombosis, Circulation 1973; 48: 619-23.

27 Renaud S, Dumont E, Baudier F, Ortchanian E, Symington IS. Influence of cigarette smoking and saturated fats on platelet function in farmers from east and west Scotland (abstract). Circulation 1980; 62 (part II), Suppl III 97.

Requests for reprints to Dr S Renaud, INSERM, U. 63, 22 avenue du Doyen Lépine, 69500 Bron, France. 